\title{
Electricity Production from Wind Energy By Piezoelectric Material
}

\author{
İkram Büyükkeskinª, Sezai Alper Tekin ${ }^{b}$, Seyfettin Gürel ${ }^{a^{*}}$, Mustafa Serdar Gença \\ a Erciyes University, Department of Energy Systems Engineering, Kayseri, Turkey \\ ${ }^{b}$ Erciyes University, Department of Industrial Design Engineering, Kayseri, Turkey
}

\begin{abstract}
In recent years, the energy demand has increased, and alternative way of energy production methods are proposed to deal with this phenomenon by scholars. One of the most promising method is piezoelectric materials. These materials can be used for energy production with improving their efficiencies. This work is made with the guidance of one project which aimed to electricity production form wind energy. This method with one prototype is investigated. Two different wind stalk structures are produced with 3-D Printer. These different structures are set up in wind tunnel and it is experimented under different wind speeds and high turbulence flows. As a result, a circular and four-corner wind stalk structures are investigated for low and high turbulence flows in several wind speeds. To conclude, the produced energy is too small for the systems in market because there are many types of piezoelectric materials for various applications and the problems due to measurement devices. However, piezoelectric materials can be better alternative for classical wind turbines in turbulence flow areas. Therefore, the electricity production from piezoelectric material will be promising method in the future with its advantages.
\end{abstract}

(C) 2019. CBIORE-IJRED. All rights reserved

Keywords: Electricity Production, Piezoelectric Material, Wind Energy, Wind Stalk, 3D Printer

Article History: Received May 15 th 2018; Received in revised form September 14 ${ }^{\text {th }}$ 2018; Accepted January $5^{\text {th }}$ 2019; Available online How to Cite This Article: Buyukkseskin, I., Tekin, S. A., Gurel, S., Genc, M S. (2019) Electricity Production from Wind Energy By Piezoelectric Material. International Journal of Renewable Energy Development, 8(1), 41-46.

https://doi.org/10.14710/ijred.8.1.41-46

\section{Introduction}

In renewable energy systems, solar, wind and hydroelectric energy sources are mainly still used for electricity production. There are a lot of methods to produce clean and sustainable energy in nature. Among all of them, piezoelectric materials take vital place for energy production. Piezoelectric effect appears when piezoelectric material is squeezed. This effect is related with changing in the polarization density in material. If the material is not shot circuit, it produces electricity by producing voltage through pressure. These types of crystals produce a voltage when they squeezed from different ways. However, the opposite condition is also possible. The special state of piezoelectric effect can also be seen in quartz and some specific forms of ceramics. It is probable to measure potential difference via placing two electrodes due to the electrical charge between these two different faces. With these ideas, piezoelectric effect and its reverse yields conversion of mechanical force into electrical effect.

Piezoelectric materials include ferroelectric structure. They can be produced by soma special mechanisms such as synthesis with different metals, oxides and salts. Piezoelectric materials have many examples in the applications such as PZT, barium titanite, and lithium niobite (Cohen 2008). Piezoelectric technology has been used in various areas which high technology markets such as medicine area, mechanical engineering applications, automotive sector and semiconductor technology. In daily life, piezoelectric material based piezoelectric vibration generators are used for cleaning glasses, jewel and tooth stone. Ultrasonic sensor which also includes piezoelectric material can be used to measure distance for parking a car.

In addition to these, piezoelectric material has also various application areas in literature. It is proposed and produced transparent piezoelectric film speaker for active noise lightening for ventilation purpose (Mirshekarloo et al. 2018). A system is suggested a process for executing self-excitation in an oscillator operated by a piezoelectric device not using with sensor (Tanaka et. al. 2018). A study which proved by experimental study piezoelectricbased nonlinear energy sink for wideband vibration attenuation (Silva et. al. 2018). Another study which is related to a new robotic arm controlled by sandwich piezoelectric transducers. In this design, robotic consists of three arms and four joints. Each arm includes a sandwich piezoelectric transducer and H-shaped hollow

\footnotetext{
*Corresponding address: sgurel87@gmail.com
} 
frame (Jiang et. al. 2018). There are some good ideas which offers good idea to implement multimodal piezo transducers (Donoso and Bellido 2018). Another study which analysed the synergistic performance of piezoelectric transducer and asphalt pavement via finite element analysis (Zhao et. al. 2018). A new structure is designed and experimented a novel stepping piezoelectric actuator to get linear driving via long blow and high resolution (Chen et. al. 2018). In another study, it is designed modified morphology density to cope with undesirable layouts during piezoelectric material production (Yoon et. al. 2018).

In some applications, the detection of defects is important in various structures building, aircraft and other many constructions. To specify the defects correctly, acoustic emission systems are used for detecting and converting this signal into electrical signals (Nair and Cai 2010). It is presented detailed study about advances and improvements in piezoelectric MEMS vibration energy harvesters (Todaro et al. 2017). Moreover, a system is proposed and designed piezoelectric MEMS sensors for elastical waves emitted by active flaws (Kabir et al. 2018). A piezoelectric energy harvesting via friction-induced vibration both experimentally and theoretically is examined (Wang et al. 2018). It is propounded a new and elastic design for lead zirconate titanate piezoelectric membrane structure so as to reduce blocking effect (Kuscer et al. 2018).

Nowadays, the piezoelectric material-based energy harvesting systems are also under investigation by scholars. These applications span from ocean energy to triboelectric nanogenerators. It is suggested an innovative beam-column piezoelectric based energy harvesting from ocean wave energy (Nabavi et al. 2018). It is also investigated ferroelectrics based fluorocarbon polymers. The most important feature of this material is that it has very large low frequency transverse piezoelectric coefficients (Zhang et al. 2018).

Also, many piezoelectric systems have been under investigation for harvesting energy and piezoelectric based energy production is novel and promising way to energy production (Buyukkeskin 2018). There is a sample project about producing electricity from piezoelectric material. In this project, it is going to get electricity with placing piezoelectric material for charging a battery at shoe sole while walking and it produces electricity because of the pressurization.

In this work, it is investigated the electricity production potential of piezoelectric generator under wind swing. In order to test the energy production, a prototype which is used in wind tunnel in Wind Engineering and Aerodynamics Research Group's laboratory. The prototype is examined for two different wind stalks for the shapes circular and four-corner. After experiments performed, it is summarized that the amount of energy which is taken into consideration for different cases is too small to use as an electricity [20].

\section{Experimental method and set-up}

\subsection{Experimental method}

During this study, it is analysed the characteristics of piezoelectric generators under wind and the amount of electricity production. It is produced two different wind stalks for the shapes circular and four-corner. It is placed
4 piezoelectric generators between $90^{\circ}$ angle each of them. It is measured with 4 Multimeter for different wind speeds in low turbulence. Afterwards, it is placed one obstacle in front of the stalk to make low turbulence to high turbulence. This procedure is applied for both circular and four-corner stalks. Comparing with measurements for different wind speeds, it is examined electricity production for low and high turbulence wind flows and the best efficient stalk type among various wind stalks. After experiments performed, it is made power analysis according to measured current and voltage values with analysing data which is taken from experiments. These data are used for the maximum power in $1 \mathrm{~cm}^{2}$ area. The technical specifications for used piezoelectric material is given in Table 1 .

Table 1

The properties of used piezoelectric material

\begin{tabular}{ll}
\hline Product Name & $\begin{array}{l}\text { Piezoelectric } \\
\text { ceramic power } \\
\text { module }\end{array}$ \\
\hline Dimensions & $35 \mathrm{~mm}$ (diameter) \\
Output Voltage & $15 \mathrm{~V}$ DC Maximum \\
Maximum Output Current & $5 \mathrm{~mA}$ \\
Rezonance Impedance & $<90 \mathrm{ohm}$ \\
Static Capacitance & $65-79 \mathrm{nF}$ \\
Bottom Layer Material & Brass $\mathrm{CW} 617 \mathrm{~N}$ \\
Copper Thickness & $0.26 \mathrm{~mm}$ \\
Piezoelektrik Ceramic Thickness & $0.30 \mathrm{~mm}$ \\
Piezoelektrik Ceramic Material & P5-6 \\
\hline
\end{tabular}

After having piezoelectric materials, it is produced stalk and base components of wind stalk via 3-D printer from Industrial Design Engineering Department in Erciyes University. The dimensions of wind tunnel are taken into consideration while designing for the wind stalk prototype. As a result, it is decided to produce stalk's length $20-25 \mathrm{~cm}$. It also determined a width and the sizing of base of wind stalk according to four piezoelectric materials which will be placed the base of wind stalk. The drawings of the system are made with the help of SolidWorks Program. The images and scaling for designed wind stalk are given Figure 1.

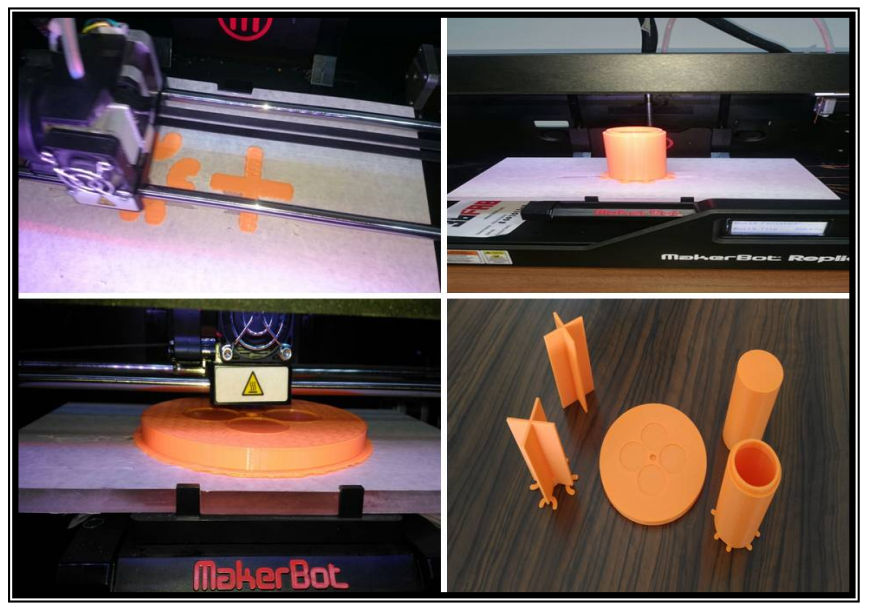

Fig 1. The Solidworks Drawings for base and stalk designs.

It is completed the production of base and stalk designs with uploading Solidworks drawings into 3-D Printers. The images which is related to production phase and the last version of products is given Figure 2. 


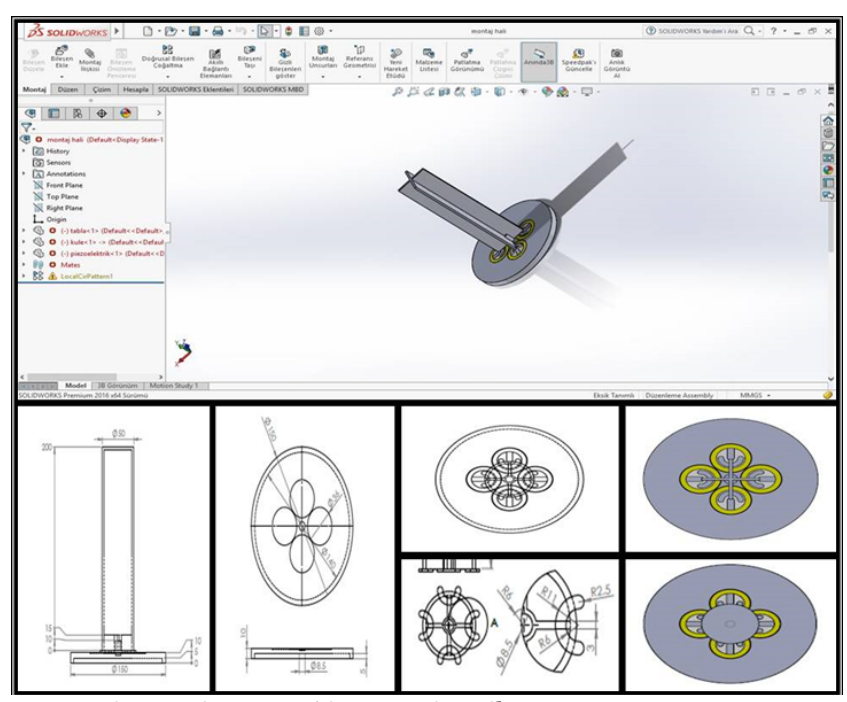

Fig 2. The production of base and stalks in 3-D Printer

Finally, it is performed wind tunnel experiments in Wind Energy Laboratory in Energy Systems Engineering Department. This wind tunnel has the properties of suction type, open cycle 50x50 cm test chamber. The speed control of the tunnel is done by external control unit and the power of tunnel $15 \mathrm{~kW}$ and revolution 1500 $\mathrm{rpm} / \mathrm{min}$. The test chamber of tunnel is made by flexiglass material and it is suitable for different applications. The other parts of tunnel are metal (Karasu, 2011). During the experiments, it is placed the stalks and measurement devices into transparent part of tunnel and recorded a video. Then, it is determined the result of measurement with watching this video records. These measurements are used for determining electricity production potential at different wind speeds. The wind tunnel in which the experiments are performed is shown in Figure 3.

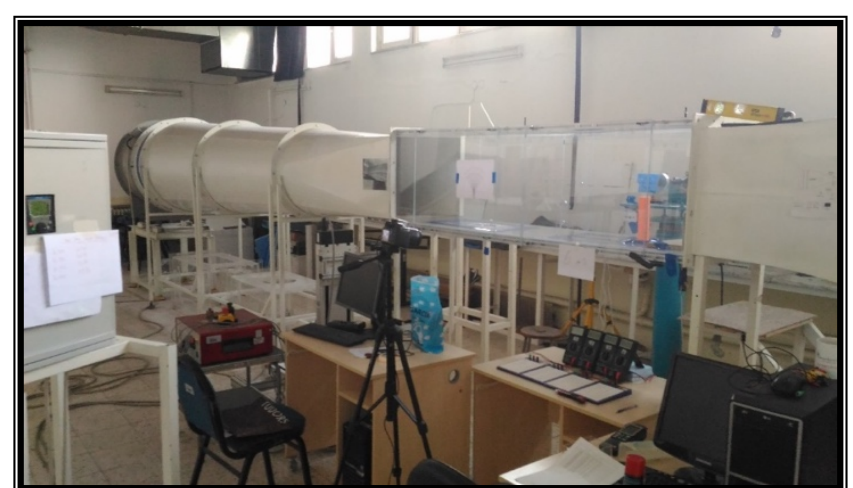

Fig 3. The wind tunnel where the experiments are performed

The wind speed is used with calculating as a meter/second for wind tunnel measurements. It is used pitot tube and this is necessary for determining wind speed with calculating difference between internal pressure and external pressure. Figure 3 was used for this process.

\subsection{Experimental Set up}

It is located four piezoelectric generators into base of talk with glue in the holes. There is only one base produced for all experiments. The four corner and circle stalks are only replaced for each measurement. It is placed stalk to the base with a swing. This swing makes easier to oscillation and it is very easy to relocate the stalk when the wind stops. Piezoelectric generator has rectifier circuits. The $1 \mathrm{~m}$ cable is connected to the output of piezoelectric generator and this makes the system easier when the current and voltage measurements is taken. A prepared experimental set up is fixed into isolate bands and piezoelectric generators are connected to test devices via cables.

\subsection{Experimental Findings}

There are two different cases which are circle stalk and four corner stalks investigated via experimental set-up. In the first experimental set-up, a wind speed is fixed at $15 \mathrm{~m} / \mathrm{s}$ due to possible problems on a prototype wind stalk in high speeds. The measurements are made from $2^{\text {nd }}$ piezoelectric generator because this is suitable for low and high turbulence. Figure 4 shows the comparison of current values of high and low turbulence flows. It is obvious that the current production is higher than low turbulence flows due to the working principle of piezoelectric material. This device works better, since it can produce more current in continuous variable pressure

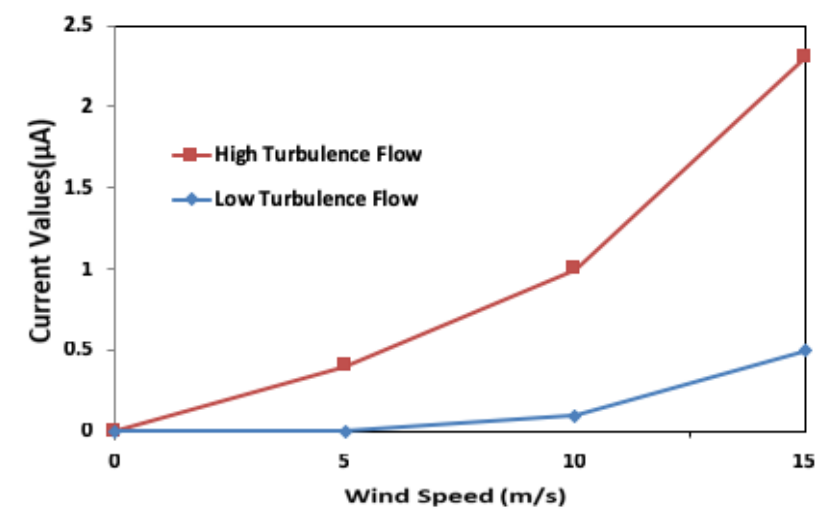

Fig 4. The comparison of maximum current production in low and high turbulence flows

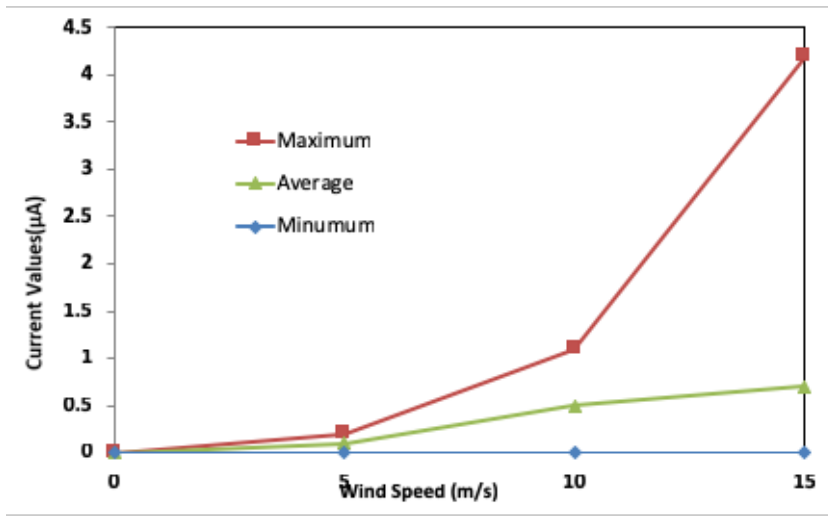

Fig 5. The Current Measurement for 4 Corner Stalk in High Turbulence Flows (DC)

In second case, four corner stalk structure is examined with making new measurements. The goal of the change the stalk structure is to explore how the aerodynamic difference affect current creation. It is measured current production for high turbulence flows 
by multimeter as Direct Current (DC). Figure 5 illustrates the four-corner stalk structure measurement in high turbulence flows. In this graph, it is clearly seen that the measurements are not suitable to see the differences in current production in DC measurements. Therefore, it is decided to remeasure in Alternative Current (AC) to see the variation in current production in the system. Figure 6 shows the AC measurements for 4 Corner Stalk in high turbulence flows.

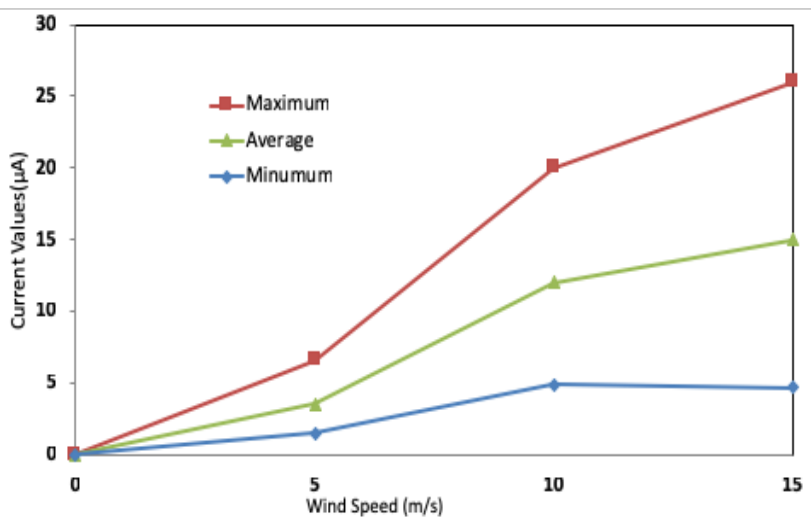

Fig 6. The Current Measurement for 4 Corner Stalk in High Turbulence Flows (AC)

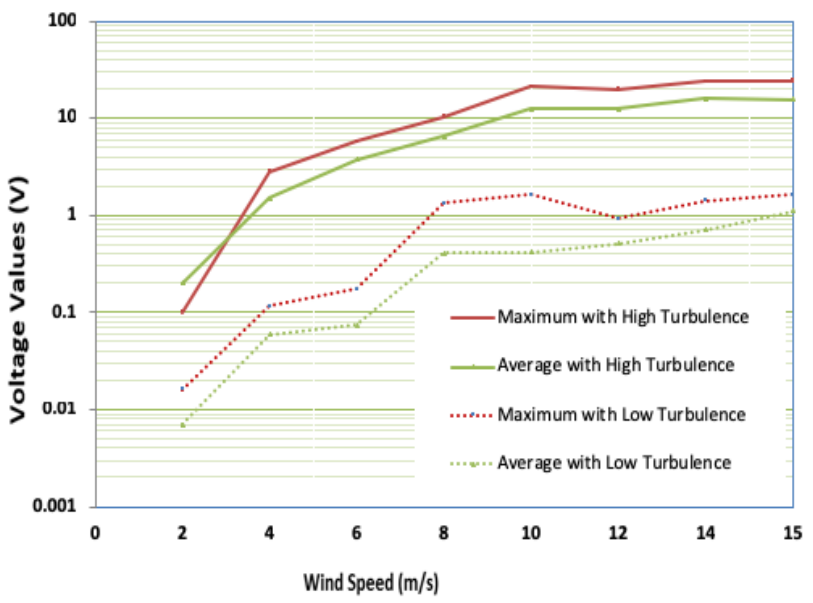

Fig 7. The Comparison of Voltage Measurement in in low and high turbulence flows for 4 Corner Stalk

The same procedure is also followed to measure voltage production in four corner and circular stalk designs. The measurements are made for two cases in high and low turbulence flows for each piezoelectric generator connected with separate multi-meters. It is given comparison of maximum average voltage measurements results in Figure 7 for four corner stalk design.

In addition to this, the circle stalk design is also examined up to $18 \mathrm{~m} / \mathrm{s}$ wind speed. After making experiments for this structure in low and high turbulence flows, it is summarized that there is a huge variety between high and low turbulence flows. Figure 8 depicts the comparison of low and high turbulence for Circle Stalk The main reason of this change is that only one piezoelectric generator produces voltage due to constant force exerted on it. This corresponds to produce low voltage production. However, it is produced more voltage in high turbulence flows owing to continuous variable pressure for all piezoelectric generators.

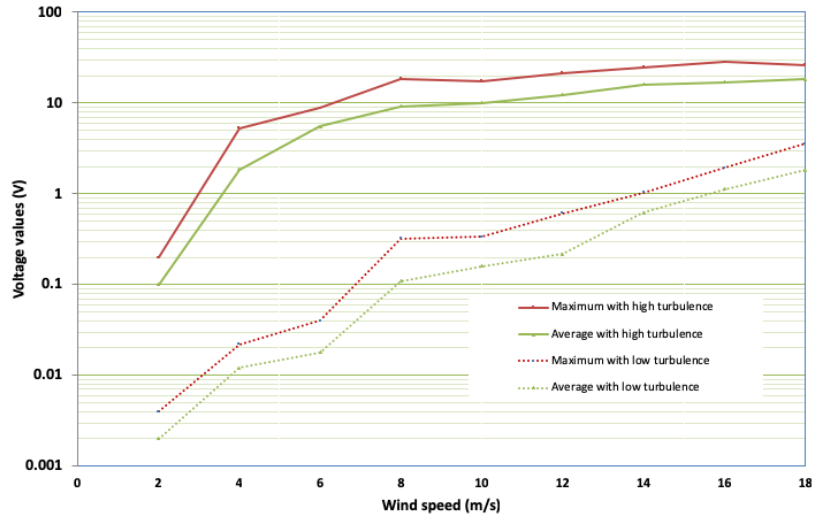

Fig 8. The Comparison of Voltage Measurement in low and high turbulence flows for Circle Stalk

If it is examined circle stalk and four corner stalk structures, the maximum and average voltages value of circle stalk structure has less better voltage values than four corner stalks in high turbulence flows. These results are examined with four piezoelectric generator's voltage values and it is indicated in Figure 9.

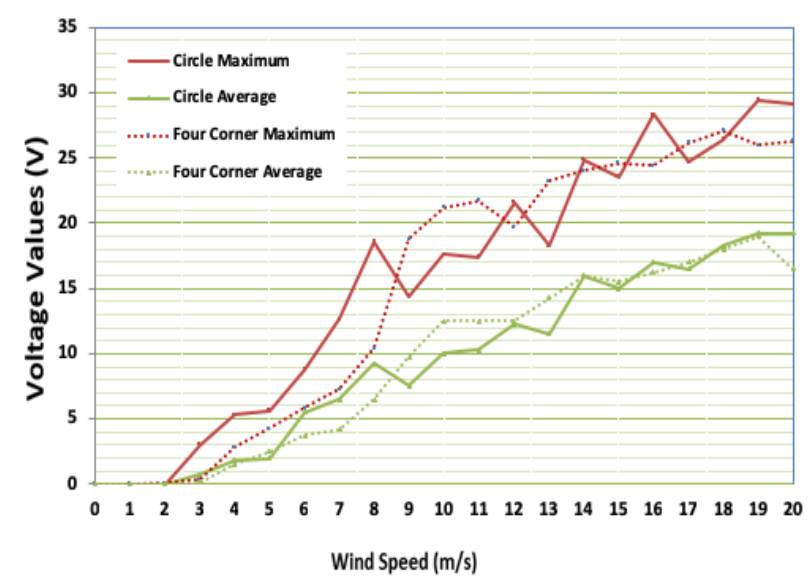

Fig 9. The Comparison of Voltage Measurement in high turbulence flows for Circle Stalk

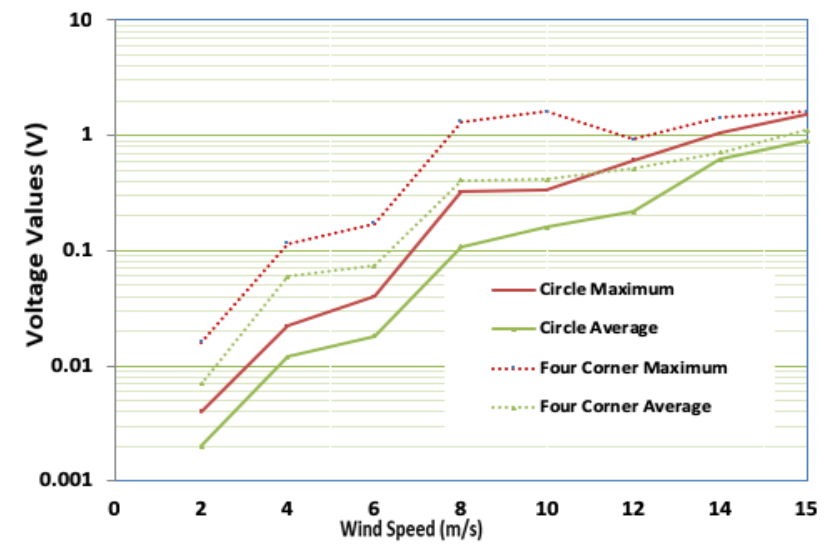

Fig 10. The Comparison of Voltage Measurement in high turbulence flows for Circle Stalk

If it is again compared two stalk structure in low turbulence flow, the four-corner stalk structure again less better than circle stalk structure in general. Figure 
10 depicts these measurements for circle and four corner stalks.

It is connected measurement devices to each piezoelectric generator. It is also analysed maximum voltage production from piezoelectric generators separately for low turbulence flow and high turbulence flows. Figure 11 shows voltage measurement results for four corner stalk structure in low turbulence.

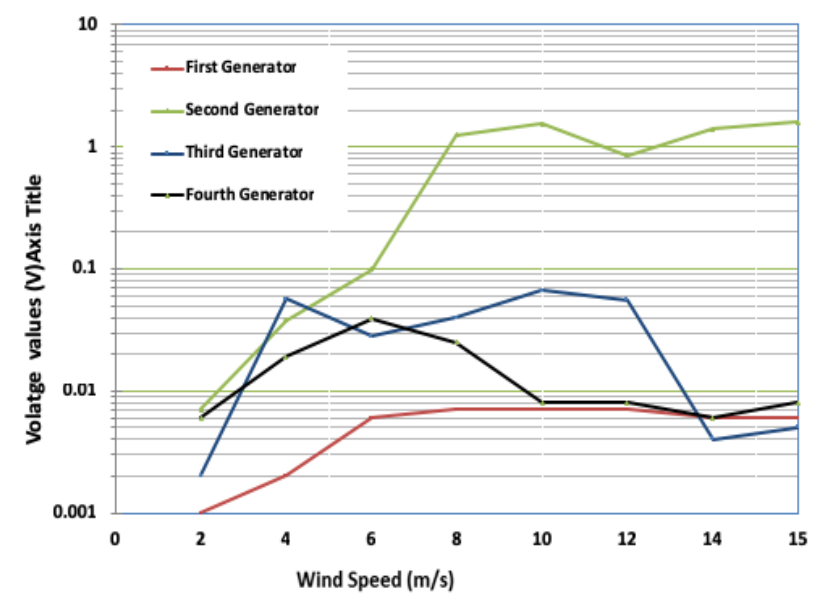

Fig 11. The Comparison of Voltage Measurement in low turbulence flows for four corner stalk

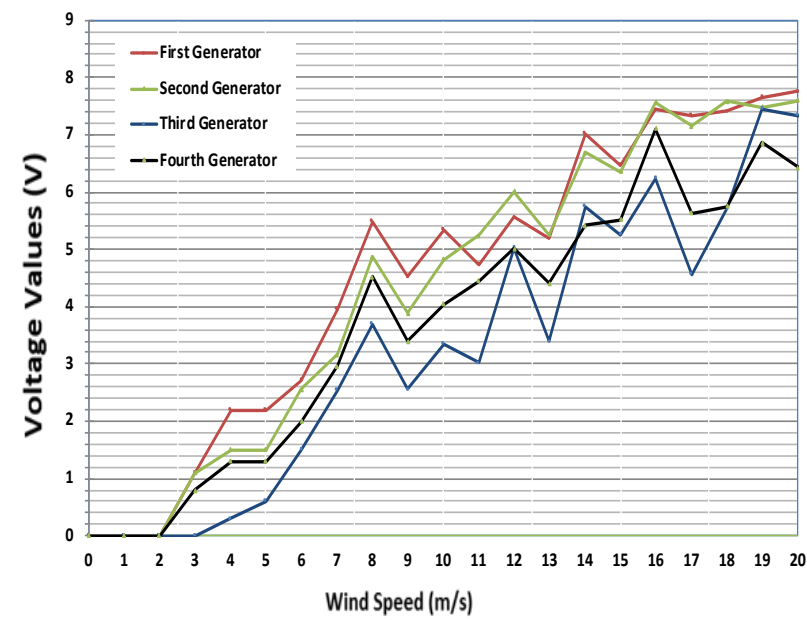

Fig 12. The Comparison of Voltage Measurement in high turbulence flows for four corner stalk

In high turbulence flow, the second generator which is against to the wind reaches has the maximum voltage production. Other generators are measured approximately similar voltage values. The voltage production values get too small values when it is compared to high turbulence flow voltage values. Figure 12 displays voltage testing values for four corner stalk in high turbulence values.

The Power production is also investigated with experimental data for $1 \mathrm{~cm}^{2}$ area. With using results of the experiments, it is calculated Power Density for 0.67 $\mathrm{cm} 2$ area. Figure 13 illustrates maximum power in $1 \mathrm{~cm}^{2}$. The maximum value appears $17 \mathrm{~m} / \mathrm{s}$ with the power density $380.73 \mu \mathrm{W} / \mathrm{cm}^{2}$.

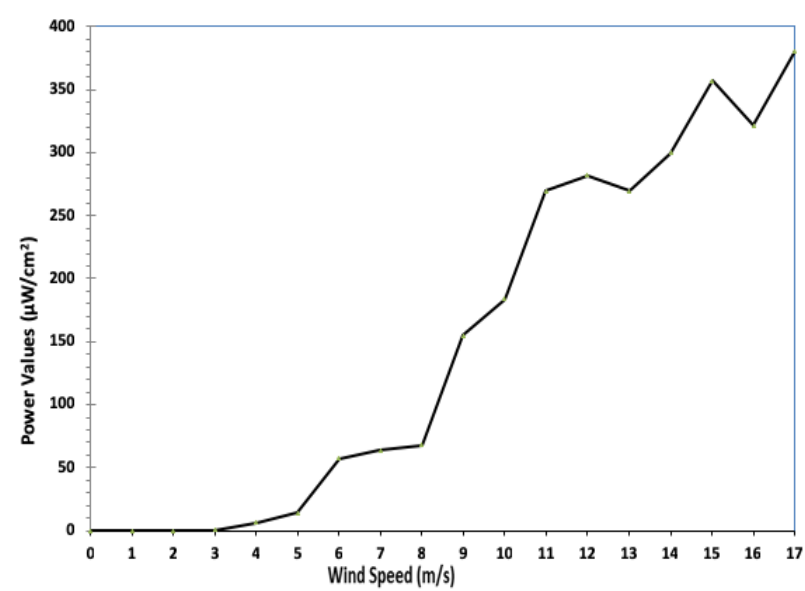

Fig13. The Maximum Power Production in $1 \mathrm{~cm}^{2}$ area

\section{Conclusions and Discussions}

In conclusion, the maximum power that achieved at 17 $\mathrm{m} / \mathrm{s}$ wind speed is $380.7373 \mu \mathrm{W} / \mathrm{cm}^{2}$. This value should be $15.3 \mathrm{~mW} / \mathrm{cm}^{2}$ according to technical data. Therefore, the efficiency of piezoelectric material is $2.5 \%$ from experimental results. The reason of this efficiency value is that the level of current must be approximately $1 \mathrm{~mA}$, but it is only $34 \mu \mathrm{A}$ from measurements.

In addition to this, it is added extra mass to above the stalk to rise the current values of the stalk. However, there is no significant effect on current value of tower. Since the current values are small, the shortening of the cable to minimize the losses that could be caused by the internal resistance of the cables did not provide an increase in the expected results. However, it is observed that there is instant luminosity in a red LED during experimental tests. This reality shows that the current power of produced power reaches milliampere current levels. Otherwise, it is not possible to get no luminosity from red LED. It will be better to assess and record the measurements by computer-controlled measurement devices.

In the future, piezoelectric materials will be most attractive subject for clean energy production. In this working, wind stalk is investigated with producing a prototype because this application is the most suitable instead of using wind turbines in the future. There are many advantages for wind stalks when it is compared to wind turbines such as high cost, eco-friendly and easy to implement with local sources. There is an important advantage of using wind stalk is that this structure can be also used in turbulence flows whereas wind turbines cannot operate efficiently.

Additionally, piezoelectric materials can be used as a multi-layer structure. As it is analysed in this study, it is possible to produce more energy with using more piezoelectric generator. Consequently, piezoelectric materials are the promising way to produce clean and energy for scholars and energy production interests

\section{Acknowledgments}

The authors acknowledge the experimental facilities and 3-D Printer laboratories for Erciyes University. 


\section{References}

Büyükkeskin, I. (2018) Electricity Production from Wind Energ with Piezoelectric Materials, M.Sc. Thesis, Graduate School of Natural and Applied Sciences, Erciyes University

Chen, W., Liu, Y., Liu, Y., Tian, X., Shan, x., Wang, L. (2018) Design and experimental evaluation of a novel stepping linear piezoelectric actuator. Sensors and Actuators A, 276, 259-266.

Cohen, R. (2008) First Principles Theories of Piezoelectric Materials, Carnegie Institution of Washington, Washington, D.C. USA

Donoso, A., Bellido, J. C. (2018) Robust design of multimodal piezoelectric transducers. Computer methods In Applied Mechanics and Engineering, 338, 27-40.

GTZ (undated) Biogas Community Plants Manual.

Jaing, Z., Wang, L., Jin, J. (2018) A novel robotic arm driven by sandwich piezoelectric transducers. Ultrasonics, 84, 373381.

Kabir, M., Kazari, H., Ozevin, D. (2018) Piezoelectric MEMS acoustic emission sensors. Sensors and Actuators A, 279, 53-64.

Karasu, İ. (2011) Experimental and Numerical Investigations of Transition to Turbulence and Laminar Separation Bubbl Over Aerofoil at Low Reynolds Number Flows. MSc. Thesis, Erciyes University.

Kuscer, D., Rojac, T., Darko, B., Zarnik, M. S., Bradsko, A., Kos, T., Malic, B., Boerrighter, M., Martin, D. M., Faccini, M. (2017) Integrated piezoelectric vibration system for fouling mitigation in ceramic filtration membranes, Journal of Membrane Science ,540, 277- 284.

Mirshekarloo, M.S., Tan, C.Y., Yu, X., Zhang, L., Shuting, C., Yao, K., Cui, F., Pandit, S.M., Chong, S.H., Tan, S.T. (2018) Transparent piezoelectric film sepakers for windows with active noise mitigation function. Applied Acoustics, 137, 90-97.
Nabavi, S. F., Farshidianfar, A., Afsharfard, A. (2018) Novel piezoelectric based ocean wave energy harvesting from offshore buoys. Applied Ocean Research, 76 ,174-187.

Nair, A., Cai, C. (2010) Acoustic emission monitoring of bridges: review and case studies, Eng. Struct. 32 (6), 1704-1714.

Silva, T. M. P., Clementino, M. A., Junior, C. D., Erturk, A. (2018) An experimentally validated piezoelectric nonlinear energy sink for wideband vibration attenuation, Journal of Sound and Vibration.

Tanaka, Y., Kpokubun, Y., Yabuno, H. (2018) Proposition for sensorless self-excitation by a piezoelectric device, Journal of Sound and Vibration, 419, 544-557.

Todaro, M. T., Guido, F., Mastronardi, V., Desmaele, D., Epifani,G., Algieri, L., Vittorio, M. D. (2017) Piezoelectric MEMS vibrational energy harvesters: Advances and outlook. Microelectronic Engineering ,183-184, 23-36.

Wang, D. W., Mo, J. L., Wang, X. F., Ouyang, H., Zhou, Z. R. (2018) Experimental and numerical investigations of the piezoelectric energy harvesting via friction-induced vibration. Energy Conversion and Management, 171, 1134-1149.

Yoon, G. H., Choi, H., Hur, S. (2018) Multiphysics topology optimization for piezoelectric acoustic focuser. Computer methods In Applied Mechanics and Engineering, 332, 600623.

Zhang, X., Pondrom, p., Sessler, G. M., Ma, X. (2018) Ferroelectret nano generator with large transverse piezoelectric activity. Nano Energy, 50, 52-61.

Zhao, H., Qin, L., Ling, J. (2018) Synergistic performance of piezoelectric transducers and asphalt pavement. International Journal of Pavement Research and Technology,11, 381-387. 